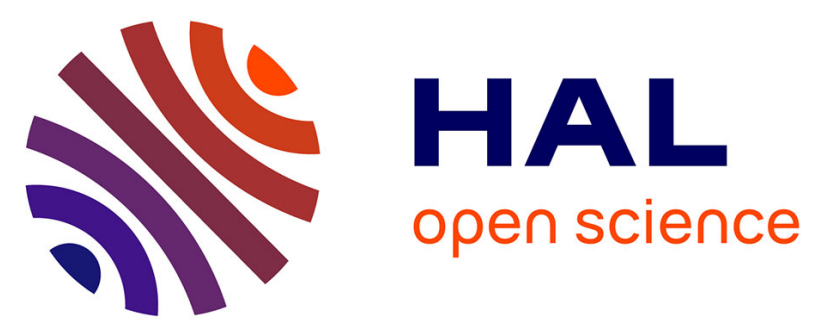

\title{
Positive and negative life events and reasons for living modulate suicidal ideation in a sample of patients with history of suicide attempts.
}

Camélia Laglaoui Bakhiyi, Isabelle Jaussent, Séverine Beziat, Renaud F. Cohen, Catherine Genty, Jean-Pierre Kahn, Marion Leboyer, Pascal Le Vaou, Sébastien Guillaume, Philippe Courtet

\section{To cite this version:}

Camélia Laglaoui Bakhiyi, Isabelle Jaussent, Séverine Beziat, Renaud F. Cohen, Catherine Genty, et al.. Positive and negative life events and reasons for living modulate suicidal ideation in a sample of patients with history of suicide attempts.. 2017. inserm-01442505

\section{HAL Id: inserm-01442505 https://www.hal.inserm.fr/inserm-01442505}

Preprint submitted on 20 Jan 2017

HAL is a multi-disciplinary open access archive for the deposit and dissemination of scientific research documents, whether they are published or not. The documents may come from teaching and research institutions in France or abroad, or from public or private research centers.
L'archive ouverte pluridisciplinaire HAL, est destinée au dépôt et à la diffusion de documents scientifiques de niveau recherche, publiés ou non, émanant des établissements d'enseignement et de recherche français ou étrangers, des laboratoires publics ou privés. 
POSITIVE AND NEGATIVE LIFE EVENTS AND REASONS FOR LIVING MODULATE SUICIDAL IDEATION IN A SAMPLE OF PATIENTS WITH HISTORY OF SUICIDE ATTEMPTS

Camélia Laglaoui Bakhiyi, MD, Ph.D. ${ }^{1,2,3}$, Isabelle Jaussent, Ph.D. ${ }^{3}$, Séverine Beziat, Msc ${ }^{3}$, Renaud Cohen, Psy.,

Catherine Genty, MsC ${ }^{1,3,4}$, Jean-Pierre Kahn, MD, Ph.D. ${ }^{4,5}$, Marion Leboyer, MD, Ph.D. ${ }^{4,6}$, Pascal Le Vaou, MD, Ph.D. ${ }^{7}$, Sébastien Guillaume, MD, Ph.D. ${ }^{1,3,4}$, Philippe Courtet, MD, Ph.D. ${ }^{1,3,4}$

${ }^{1}$ Department of Emergency Psychiatry \& Acute Care, CHU Montpellier, Montpellier, France

${ }^{2}$ Psychiatric Unit, CHU Casablanca, Hassan II University, Casablanca, Morocco

${ }^{3}$ Inserm U1061, La Colombière Hospital, University of Montpellier, France

${ }^{4}$ FondaMental Foundation, France

${ }^{5}$ University of Lorraine, Psychotherapeutic Centre of Nancy-Laxou, France

${ }^{6}$ Department of Psychiatry and Addictology, Créteil, France

${ }^{7}$ Emergency and Liaison Psychiatry Department, CHR Metz-Thionville, France

To whom correspondence should be addressed:

Camélia LAGLAOUI BAKHIYI

INSERM U1061, La Colombière Hospital, University of Montpellier UM1, Montpellier, France

Phone number: 00212661484792

E-mail: camelia.laglaoui@gmail.com 


\section{ABSTRACT (248 words)}

Background: The influence of life events on suicidal behavior remains inconclusive, while reasons for living (RFL) may be protective.

Objectives: To analyze the association between positive and negative life events and suicidal ideation (SI) and the interaction between life events and RFL on SI.

Method: Patients with history of suicide attempts $(n=338)$ underwent a comprehensive clinical evaluation, including SI (Beck’s Suicidal Ideation scale), RFL (Reasons for Living Inventory, RFLI) and life events (family, school, student or professional, social, health and religion-related and other life events) during the last twelve months.

Results: The only negative life events associated with SI were health-related events ( $\mathrm{OR}=2.0195 \% \mathrm{CI}[1.04 ; 3.92])$. Family-related positive life events and RFL were negatively associated with SI (OR=0.73 95\%CI $[0.58 ; 0.91]$ and $\mathrm{OR}=0.9895 \% \mathrm{CI}[0.97 ; 0.98]$, respectively). No significant interaction between the number of positive life events and RFLI total score with current SI $(\mathrm{p}=0.57)$ was detected. Family-related positive life events and RFL did not have any additive effect on SI. Positive life events did not moderate the association between health-related negative life events and SI.

Limitations: This was a retrospective study, the presence of axis II disorders was not investigated and results cannot be generalized due to the sample choice (only suicide attempters).

Conclusions: Patients with history of suicide attempts could be less sensitive to negative life events, except for those related to health. Clinicians should pay more attention to somatic problems in patients at risk of suicide. Family support, positive psychology and therapies that strengthen RFL should be developed to prevent suicide.

Key words: suicide; life events; reasons for living 


\section{INTRODUCTION}

Suicide is a major public health issue. Nearly one million people die due to suicide every year. Moreover, it is generally underreported because suicide by car accident may be recorded as accidental death (more than $2 \%$ of the current traffic accidents) (Pompili et al., 2012). Evidence supports the hypothesis that recent (i.e., in the last 6-12 months) negative life events (NLE) may act as triggers of suicidal behavior (Liu and Miller, 2014). Many studies suggest that NLE may increase the risk of suicidal ideation (SI) (Casey et al., 2006), suicide attempt (SA) (BlascoFontecilla et al., 2010) and completed suicide (Vijayakumar and Rajkumar, 1999; Khan et al., 2008; Zhang et al., 2004, 2010), independently of psychiatric and personality disorders (Wang et al., 2015; Cheng et al., 2000; Li et al., 2008; Turvey et al., 2002; Wan and Leung, 2010; Yen et al., 2005). However, some findings suggest that not only life events, but a combination of several factors that contribute to SI can initiate a suicidal process (Rich and Bonner, 1987; Joiner and Rudd, 1995) or acts (Kelly et al., 2000). According to the stress-diathesis model of suicidal behavior (Mann et al., 1999; Oquendo et al., 2004), suicide might be the result of the interaction between environmental stressors or psychiatric disorders and trait-dependent vulnerability to suicidal behavior. Particularly, studies on the vulnerability stress model suggest that psychological pain, pessimism, impulsivity and early trauma may predispose to suicidal behavior by influencing the ability to cope with NLE (Olié et al., 2010; Jorge LopezCastroman et al., 2014a).

For instance, it has been demonstrated that suicide acceptance increases significantly the probability of planning suicide among people who experience hopelessness (Joe et al., 2007). Several studies have stressed that besides NLE, psychiatric disorders also may play a major and possibly greater role in increasing suicide risk (Abreu et al., 2009; Oquendo et al., 2004; Goldney et al., 2000). However, it was recently reported that this is true in men but not in women and that, consequently, NLE are an independent risk factor for suicidal ideation and behavior only in women (Park et al., 2015). Moreover, some studies did not find a consistent link between NLE and SA (De Vanna et al., 1990). In addition, little is known about protective factors because few studies focused on them and results were not conclusive (Liu and Miller, 2014). The Reasons For Living Inventory (RFLI) has been developed to identify protective factors against suicide (Linehan et al., 1983). Reasons for living (RFL) are reasons that an individual may consider important for "staying alive" and "not killing himself/herself". Linehan et al. postulated that having many RFL could act as a protective factor against suicide. Data on the protective role of positive life 
events (PLE) also are scarce. It has been proposed that PLE and social support, which is a potential protective factor, might modulate SI and act synergistically to buffer NLE effect on SI (Kleiman et al., 2014). Similarly, resilience factors (i.e., potential protective factors against suicide) could interact together to reduce the risk of suicide.

In this study, we investigated the association between positive and negative life events and current SI in a sample of patients with history of SA. We focused on this specific population because individuals with history of SA are at very high risk of suicide. Moreover, this risk is proportionally higher in the case of recent suicide attempt (Carroll et al., 2014). We hypothesized that: (1) NLE increase SI occurrence; (2) PLE and RFL are protective against SI appearance; and (3) RFL and PLE have a synergistic protective effect against SI (i.e., the combined effect of RFL and PLE is higher than the sum of the effects of each of these variables). By performing a comprehensive assessment of the environmental factors that may modulate SI, we wanted to collect useful information for developing specific patient-centered psychosocial interventions.

\section{METHODS}

\section{Participants}

For this study, hospitalized patients with history of SA were consecutively recruited at the Adult Psychiatry Departments of Montpellier University Hospital Center (Lapeyronie Hospital), Créteil University Hospital Center (H. Mondor and A. Chenevier Hospitals) and Nancy University Hospital Center (Jeanne d'Arc Hospital, Toul), France. All patients had a lifetime history of SA, but hospitalization at the time of inclusion was not necessarily due to a SA. A SA was defined as a self-destructive act with some degree of intent to end one's life (according to the definition given by Mann \& al., 1999). This is different from self-harm and requires medical evaluation or treatment. Patients were enrolled if they were older than 18 years of age, French speaking and with all four biological grandparents originating from Western European countries (for genetic studies). Exclusion criteria were: pregnancy, breast-feeding, patients involved in another research protocol or for whom the maximum annual payments $(3,800 €)$ for participation in clinical studies was reached, minors, patients not affiliated to a French social security system, legally protected individuals, patients deprived of freedom by judicial or administrative decision, or absence of informed consent to participate in the study. After having received information about the study purpose and method, patients signed an informed consent form. The study was approved by the local Ethics 
Committee (CPP Sud Méditerranée IV, CHU Montpellier). In total, 338 patients with available data on life events, SI and RFL were included in this study.

\section{Assessment}

Clinical assessments by trained psychiatrists included a full medical examination as well as evaluation of impulsivity, SI, hopelessness, RFL, life events, personal or familial history of suicidal behavior and history of childhood maltreatment. The validated French version of the Mini International Neuropsychiatric Interview was used to identify Axis I-DSM IV disorders (Sheehan et al., 1998). Depression was assessed with the French version of the Beck Depression Inventory (BDI) (Beck et al., 1961; Collet and Cottraux, 1986). Participants completed the following self-report questionnaires:

- the 10th version of the Barratt Impulsiveness Scale (BIS-10) (Barratt, 1965; Baylé et al., 2000). This is a widely used and validated 34-item and 4-point Likert scale with documented internal consistency (Patton et al., 1995). High scores indicate high level of impulsivity.

- the 19-item Beck's Suicidal Ideation scale (SSI) (Beck et al., 1979). Scores for each item range from 0 to 2 and the total score from 0 to 38 . High scores are correlated with high SI levels. The cut-off of 2 is considered as the best to distinguish between suicidal and non-suicidal subjects (de Beurs et al., 2015). This scale is widely used by clinicians to assess suicidal thoughts and to follow the patient's response to treatment. Its reliability and validity have been documented. This scale was used to measure SI at the time of inclusion in the study.

- the Beck Hopelessness Scale (BHS). This widely used, 20-item self-report questionnaire has been designed to measure "three major aspects of hopelessness: feelings about the future, loss of motivation and loss of expectations" (Kattimani et al., 2015). It is highly reliable and has been validated (Beck et al., 1974).

- the Childhood Trauma Questionnaire (CTQ) (Bernstein et al., 1994). The CTQ is used to identify retrospectively five types of childhood maltreatment (physical abuse, emotional abuse, sexual abuse, physical neglect and emotional neglect) that are categorized as none, low, moderate or severe.

- the Reasons for Living Inventory (RFLI) (Linehan et al., 1983). RFLI is a validated instrument to assess reasons that a person considers important for not killing himself/herself. It is a 48-item, 6-point Likert scale with six subscales: Survival and Coping Beliefs (SCB), Moral Objections to Suicide (MOS), Responsibility to Family (RF), Child-related Concerns (CC), Fear of Suicide (FOS) and Fear of Social Disapproval (FSD). 
Life events were assessed with an exhaustive checklist we used in a previous study (Jollant et al., 2007). This checklist includes four subscales: "Family-related life events", "School-, student- or profession-related life events", "Social, religious and other life events", and "Health-related life events". It is an instrument based on a 6-point Likert subscale. Patients were asked by the interviewer to assign a score (from -3 to +3 ) to each event experienced during the last 12 months, according to the effects and feelings generated by this event. Therefore, the same event could be rated as positive by a patient and as negative by another patient. Events with negative scores were considered as NLE and events with positive scores were considered as PLE.

Clinicians evaluated each patient's personal history of suicidal behavior by asking about the lifetime number of SA ( 1 or 2 vs. $\geq 3$ ) and age at the first SA (categorized as $>26$-year-old or $\leq 26$-year-old, based on a previous study by our group (Slama et al., 2009)). Participants were also asked about family history of suicidal behavior.

Patients' selection and assessment were similar in the three centers that participated in the study.

\section{Statistical analysis}

The sample was described using percentages for categorical variables and medians and ranges for quantitative variables (age, number of PLE and NLE) after ascertaining with the Shapiro-Wilk test that their distribution was skewed. To assess the relationship between the patients' sociodemographic and clinical characteristics and current SI, patients were divided in two groups on the basis of their current SSI score: $<2$ (corresponding to the higher tertile of the SSI distribution and considered as patients without SI) and $\geq 2$ (considered as patients with SI).

For comparisons between groups, univariate logistic regression analyses were performed. Odds ratios with $95 \%$ confidence interval (CI) and the associated p-values were reported. Multivariate logistic regression analysis was used to test associations between life events and presence/absence of current SI. All variables with p-values $<0.10$ in the univariate analysis were considered as potential candidates. When appropriate (for example, when the number of PLE and of NLE was significantly associated with current SI), the interaction terms were tested using the Wald $\chi 2$ test given by the logistic regression model.

Significance level was set at $\mathrm{p}<0.05$. All analyses were performed using the SAS statistical software (version 9.4; SAS Inc, Cary, North Carolina). 


\section{RESULTS}

\section{Descriptive data:}

The final sample included 338 patients (237 patients from Montpellier, 60 from Nancy and 41 from Créteil). Most participants were women $(n=220 ; 65 \%)$, the mean age was 42.50 years $(\mathrm{SD}=12.30), 45 \%$ were single and $67 \%$ had twelve years or more of education. Moreover, $29 \%$ had a bipolar disorder, $67.5 \%$ a major depressive disorder, $57 \%$ were considered as severely depressed (BDI score $\geq 15$ ), $18 \%$ had a substance use disorder and $33 \%$ alcohol dependence. In our sample, $35 \%$ of patients had never smoked, $17 \%$ had smoked previously and $48 \%$ were current smokers. The mean delay between the SA date and the current hospitalization was 11 months and 12 days $(\mathrm{SD}=4$ years 5 months and 23 days, $\min =0, \max =37$ years); $92 \%$ of patients had attempted suicide during the current year and $38 \%$ had SI (SSI score at inclusion $\geq 2$ ).

\section{Socio-demographic and clinical characteristics in patients with or without SI:}

The baseline sociodemographic and clinical characteristics in patients with and without SI (based on the SSI cut-off of 2) were comparable with the exception of sex (women were more numerous in the $\mathrm{SSI} \geq 2$ group) and depression (the percentage of patients with severe depression was higher in the group with than without current $\mathrm{SI})(\mathrm{p}<0.0001$ both comparisons) (Table 1). No significant difference was detected concerning the health status and substance abuse.

Suicidal behavior, personality traits and childhood trauma in patients with or without current SI:

Compared with patients without SI, patients with SI reported more SAs $(p=0.0001)$, had higher scores for impulsivity (BIS-10 total score, non-planning impulsiveness and motor impulsiveness scores) $(\mathrm{p}=0.003, \mathrm{p}=0.005$ and $\mathrm{p}=0.002$ respectively) and hopelessness (BHS) $(\mathrm{p}<0.0001)$. They also had more often experienced childhood emotional abuse $(\mathrm{p}=0.03)$. Conversely, the reported frequency and severity of other types of childhood abuse and childhood neglect were not significantly different in the two groups (Table 2).

\section{Life events, reasons for living and current SI:}

Table 3 reports the associations between life events or RFL and presence/absence of SI. Multivariate logistic regression analysis after adjustment for sex and BDI score (model 1) indicated that, compared with the SSI score $<2$ group, a current SSI score $\geq 2$ was associated with fewer PLE (all types) (OR=0.85 95\%CI[0.74-0.97]) and 
family-related PLE $(\mathrm{OR}=0.73$ 95\%CI[0.59-0.90]) and more health-related NLE (OR=1.85 95\%CI [1.02-3.36]. These results remained significant after additional adjustment for the CTQ-emotional abuse, CTQ-physical neglect and CTQ-emotional neglect scores (model 2) and also for SA number and BIS-10 score (model 3). Similarly, after adjustment for health-related NLE, the inverse association between number of family-related PLE and SI was not modified $(\mathrm{OR}=0.73$ 95\% $\mathrm{CI}=0.58-0.91$, model 2$)$.

Concerning the RFL, patients with current SI had significantly lower total and subscale RFLI scores, but for the "FOS" subscale, than patients without SI. These results remained significant after adjustment.

No significant interaction was found between total number of PLE and RFLI total score and current SI ( $\mathrm{p}=0.57)$. Finally, assessment of the effect of the family-related PLE-RFLI score combination on SI did not highlight any synergistic or additive effect (i.e., the combined effect corresponds to the sum of the effects of each variables) (Table 4).

\section{DISCUSSION}

This study shows that (1) only health-related NLE are associated with SI; (2) family-related PLE and RFL are inversely associated with SI; (3) the associations between life events (family-related PLE and health-related NLE) and SI remain after controlling for depression, impulsivity, SA number and childhood maltreatment; (4) PLE and RFL do not have an additive effect on SI; (5) PLE do not moderate the association between health-related NLE and SI.

Our results do not support the hypothesis that NLE are risk factor for SI, with the exception of health-related NLE. However, NLE have been associated with SI (Grover et al., 2009; Dupéré et al., 2009), SA (Kumar et al., 2006; Liu and Tein, 2005; Yen et al., 2005) and completed suicide (Cole et al., 1992; Zhang et al., 2004, 2010; Li et al., 2008). Moreover, suicide has been widely linked to family conflicts, professional and financial problems and interpersonal difficulties. Our finding that NLE may not increase SI risk could be explained by the sample choice. Indeed, we recruited only patients with history of SA who are at higher risk of suicidal behavior and who may engage in a suicidal process even in the absence of sufficiently severe NLE to be remembered during the kind of evaluation performed for this study. In line with this hypothesis, one recent study showed that NLE effect is not significant in suicide attempters; conversely, non-attempters were more likely to develop suicidal thoughts in the 
presence of NLE (Gvion et al., 2015). Umamaheswari et al. (2014) found that NLE do not increase SI in patients with bipolar depression and suggested that patients with severe depression might develop a process of internalization and become less sensitive to external events.

Our finding that health-related NLE are independently associated with SI is in agreement with previous reports on the link between physical problems and suicide (O'Connor and Nock, 2014; Zhang et al., 2015; Rubenowitz et al., 2001). A recent study showed that people who self-harm are at higher risk of death due to physical illnesses. Mortality due to somatic causes seems to be higher in suicidal patients (either SI or suicidal behavior) than in the general population (Bergen et al., 2012). Clinicians should be aware of this in order to improve the assessment of such patients and provide the most appropriate care (Bergen et al., 2012).

We also found that the number of PLE (especially those family-related) and high RFLI scores (total and SCB, RF, CC, FSD, MOS subscores) are significantly associated with absence of SI (SSI score $<2$ ). Very few studies have evaluated PLE effect on SI, and our results are consistent with those reported by Kleiman et al. (2014). PLE role in reducing SI could be exploited in line with the growing body of evidence on the effects of positive psychology. Specifically, the aim of short positive psychology exercises, such as writing gratitude letters or counting the blessings, is to enhance the patient's well-being (Huffman et al., 2014). For instance, in the counting the blessings' exercise, patients are asked to "recall three events in the past week for which he/she was grateful and to record them in detail" (Huffman et al., 2014). Results show that these exercises are effective in suicidal inpatients. These data and our results on PLE suggest that positive psychology interventions could strengthen PLE role in SI reduction. Research to test this hypothesis should be encouraged. Moreover, the patients' families should be informed about the importance of their support and their role in preventing SI. Concerning the inverse relationship between RFL and SI, similar findings have been reviewed recently (Laglaoui et al., 2016; Edelstein et al., 2009; Demyttenaere et al., 2014). More attention should be paid to RFL role in suicide; therapies to strengthen RFL, such as dialectical behavioral therapy (Linehan et al., 2015), could be effective in preventing suicide and in reducing the risk of suicidal thoughts and attempts.

Our study also shows that family-related PLE and RFL are individually and independently associated with SSI score $<2$, but they do not have a synergistic or additive effect on SI. Additionally, family-related PLE and RFL do not moderate the risk conferred by health-related NLE on SI. This is one of the first studies on the interaction 
between life events and RFL and on NLE and PLE interaction on SI. Additional research is needed to test interactive models that involve resilience factors (i.e., factors that may confer protection against suicide, such as coping skills, sense of self-worth or self-esteem, social support, religious, cultural and spiritual beliefs, being married or a parent) and NLE. Indeed, one recent study examined the interaction between NLE and grit, a resilience factor defined as "passionate perseverance toward long term goals, especially through obstacles and adversity" (Duckworth et al., 2007), and found that high grit moderates NLE effect on SI (Blalock et al., 2015). Similarly, coping abilities can buffer NLE effect on suicide (Sun and Zhang, 2015). These results are clinically relevant. A global evaluation of NLE and resilience factors (grit, coping skills, etc.) may help clinicians to identify patients at high risk of suicide, depending on their clinical characteristics. Moreover, more information on the resilience factors that may interact with NLE to reduce suicidal outcomes could help clinicians to develop therapies to enhance these specific resilience factors and increase protection against suicide.

Finally, our study highlights the association between high BIS-10 scores (total score, non-planning impulsiveness or motor impulsiveness) and SI. Impulsivity has been linked to suicidal acts in many studies (Brent, 2010; Brent et al., 2003; Brodsky et al., 2008, 2001; Gvion and Apter, 2011; J. Lopez-Castroman et al., 2014b; Mann et al., 2009; McGirr et al., 2009; McGirr and Turecki, 2007; Melhem et al., 2007). It could be hypothesized that impulsive individuals are more likely to experience NLE and consequently, the association between impulsivity and suicidal behavior could be indirectly explained by a greater exposure to NLE (Bender et al., 2011). This association between impulsivity and SI has never been reported in the literature. Moreover, the link between impulsivity and suicide could be deeper and not restricted only to suicidal acts. Indeed, impulsivity might operate at a cognitive level and enhance the probability to display SI. Although this result needs to be replicated, it suggests that impulsivity may be involved in all steps of the suicidal process.

\section{LIMITATIONS}

Our results should be considered with caution. The questionnaire used to assess life events was a checklist and did not take into account daily difficulties. Moreover, the retrospective investigation of life events is often affected by memory bias. Although we found a negative relationship between PLE, RFL and SI, we could not conclude that these factors are protective because our study was retrospective. Longitudinal studies are needed to confirm this hypothesis. Moreover, we did not investigate Axis II disorders and this could have biased our results. Our findings 
cannot be generalized because we enrolled only individuals with history of SA. To be generalized, our results need to be replicated in larger, clinical and community-based populations and in prospective studies.

\section{CONCLUSION}

Currently, few therapies, such as dialectical behavioral therapies and brief contact interventions, are considered to be effective for suicide prevention in individuals with history of SA (Milner et al., 2015). Here, we investigated the role of life events and potential protective factors with the aim of collecting useful information for developing new effective clinical interventions. Our findings suggest that individuals with history of SA are less sensitive to NLE, with the exception of health-related NLE. Conversely, family-related PLE and RFL were inversely correlated with SI. Therefore, clinicians should pay more attention to somatic problems in patients at risk of suicide. Moreover, family support, positive psychology exercises and therapies that help strengthen RFL, such as dialectical behavioral therapies, should be further developed to prevent suicide. Interactive models that include protective and risk factors for suicide should be tested to better understand suicide and to provide clinicians with a comprehensive assessment and management of suicidal patients.

\section{Conflict of interest}

None of the authors declare conflict of interests related to this manuscript.

\section{Role of Funding Sources}

This study received financial support from CHU Montpellier (PHRC UF 7653) and Agence Nationale de la Recherche (ANR NEURO 2007 “GENESIS”).

C. LAGLAOUI BAKHIYI received a grant from ERASMUS MUNDUS - EU METALIC II. ERASMUS MUNDUS - EU METALIC II had no role in the study design, collection, analysis or interpretation of the data, writing the manuscript, or the decision to submit the paper for publication. 


\section{REFERENCES}

Abreu, L.N. de, Lafer, B., Baca-Garcia, E., Oquendo, M.A., 2009. Suicidal ideation and suicide attempts in bipolar disorder type I: an update for the clinician. Rev. Bras. Psiquiatr. 31. doi:10.1590/S151644462009005000003

Barratt, E.S., 1965. FACTOR ANALYSIS OF SOME PSYCHOMETRIC MEASURES OF IMPULSIVENESS AND ANXIETY. Psychol. Rep. 16, 547-554. doi:10.2466/pr0.1965.16.2.547

Baylé, F.J., Bourdel, M.C., Caci, H., Gorwood, P., Chignon, J.M., Adés, J., Lôo, H., 2000. [Factor analysis of french translation of the Barratt impulsivity scale (BIS-10)]. Can. J. Psychiatry Rev. Can. Psychiatr. 45, $156-165$.

Beck, A.T., Kovacs, M., Weissman, A., 1979. Assessment of suicidal intention: the Scale for Suicide Ideation. J. Consult. Clin. Psychol. 47, 343-352.

Beck, A.T., Ward, C.H., Mendelson, M., Mock, J., Erbaugh, J., 1961. An inventory for measuring depression. Arch. Gen. Psychiatry 4, 561-571.

Beck, A.T., Weissman, A., Lester, D., Trexler, L., 1974. The measurement of pessimism: the hopelessness scale. J. Consult. Clin. Psychol. 42, 861-865.

Bender, T.W., Gordon, K.H., Bresin, K., Joiner, T.E., 2011. Impulsivity and suicidality: the mediating role of painful and provocative experiences. J. Affect. Disord. 129, 301-307. doi:10.1016/j.jad.2010.07.023

Bergen, H., Hawton, K., Waters, K., Ness, J., Cooper, J., Steeg, S., Kapur, N., 2012. Premature death after selfharm: a multicentre cohort study. Lancet Lond. Engl. 380, 1568-1574. doi:10.1016/S0140-6736(12)611416

Bernstein, D.P., Fink, L., Handelsman, L., Foote, J., Lovejoy, M., Wenzel, K., Sapareto, E., Ruggiero, J., 1994. Initial reliability and validity of a new retrospective measure of child abuse and neglect. Am. J. Psychiatry $151,1132-1136$.

Blalock, D.V., Young, K.C., Kleiman, E.M., 2015. Stability amidst turmoil: Grit buffers the effects of negative life events on suicidal ideation. Psychiatry Res. 228, 781-784. doi:10.1016/j.psychres.2015.04.041

Blasco-Fontecilla, H., Baca-Garcia, E., Duberstein, P., Perez-Rodriguez, M.M., Dervic, K., Saiz-Ruiz, J., Courtet, P., de Leon, J., Oquendo, M.A., 2010. An exploratory study of the relationship between diverse life events and specific personality disorders in a sample of suicide attempters. J. Personal. Disord. 24, 773-784. doi:10.1521/pedi.2010.24.6.773

Brent, D., 2010. What family studies teach us about suicidal behavior: implications for research, treatment, and prevention. Eur. Psychiatry J. Assoc. Eur. Psychiatr. 25, 260-263. doi:10.1016/j.eurpsy.2009.12.009

Brent, D.A., Oquendo, M., Birmaher, B., Greenhill, L., Kolko, D., Stanley, B., Zelazny, J., Brodsky, B., Firinciogullari, S., Ellis, S.P., Mann, J.J., 2003. Peripubertal suicide attempts in offspring of suicide attempters with siblings concordant for suicidal behavior. Am. J. Psychiatry 160, 1486-1493.

Brodsky, B.S., Mann, J.J., Stanley, B., Tin, A., Oquendo, M., Birmaher, B., Greenhill, L., Kolko, D., Zelazny, J., Burke, A.K., Melhem, N.M., Brent, D., 2008. Familial transmission of suicidal behavior: factors mediating the relationship between childhood abuse and offspring suicide attempts. J. Clin. Psychiatry 69, 584-596.

Brodsky, B.S., Oquendo, M., Ellis, S.P., Haas, G.L., Malone, K.M., Mann, J.J., 2001. The relationship of childhood abuse to impulsivity and suicidal behavior in adults with major depression. Am. J. Psychiatry 158, $1871-$ 1877.

Carroll, R., Metcalfe, C., Gunnell, D., 2014. Hospital presenting self-harm and risk of fatal and non-fatal repetition: systematic review and meta-analysis. PloS One 9, e89944. doi:10.1371/journal.pone.0089944

Casey, P.R., Dunn, G., Kelly, B.D., Birkbeck, G., Dalgard, O.S., Lehtinen, V., Britta, S., Ayuso-Mateos, J.L., Dowrick, C., ODIN Group, 2006. Factors associated with suicidal ideation in the general population: fivecentre analysis from the ODIN study. Br. J. Psychiatry J. Ment. Sci. 189, 410-415. doi:10.1192/bjp.bp.105.017368

Cheng, A.T., Chen, T.H., Chen, C.C., Jenkins, R., 2000. Psychosocial and psychiatric risk factors for suicide. Casecontrol psychological autopsy study. Br. J. Psychiatry J. Ment. Sci. 177, 360-365. 
Cole, D.E., Protinsky, H.O., Cross, L.H., 1992. An empirical investigation of adolescent suicidal ideation. Adolescence 27, 813-818.

Collet, L., Cottraux, J., 1986. [The shortened Beck depression inventory (13 items). Study of the concurrent validity with the Hamilton scale and Widlöcher's retardation scale]. L'Encéphale 12, 77-79.

de Beurs, D.P., Fokkema, M., de Groot, M.H., de Keijser, J., Kerkhof, A.J.F.M., 2015. Longitudinal measurement invariance of the Beck Scale for Suicide Ideation. Psychiatry Res. 225, 368-373. doi:10.1016/j.psychres.2014.11.075

De Vanna, M., Paterniti, S., Milievich, C., Rigamonti, R., Sulich, A., Faravelli, C., 1990. Recent life events and attempted suicide. J. Affect. Disord. 18, 51-58.

Demyttenaere, K., Desaiah, D., Raskin, J., Cairns, V., Brecht, S., 2014. Suicidal thoughts and reasons for living in hospitalized patients with severe depression: post-hoc analyses of a double-blind randomized trial of duloxetine. Prim. Care Companion CNS Disord. 16. doi:10.4088/PCC.13m01591

Duckworth, A.L., Peterson, C., Matthews, M.D., Kelly, D.R., 2007. Grit: perseverance and passion for long-term goals. J. Pers. Soc. Psychol. 92, 1087-1101. doi:10.1037/0022-3514.92.6.1087

Dupéré, V., Leventhal, T., Lacourse, E., 2009. Neighborhood poverty and suicidal thoughts and attempts in late adolescence. Psychol. Med. 39, 1295-1306. doi:10.1017/S003329170800456X

Edelstein, B.A., Heisel, M.J., McKee, D.R., Martin, R.R., Koven, L.P., Duberstein, P.R., Britton, P.C., 2009. Development and psychometric evaluation of the reasons for living--older adults scale: a suicide risk assessment inventory. The Gerontologist 49, 736-745. doi:10.1093/geront/gnp052

Goldney, R.D., Wilson, D., Dal Grande, E., Fisher, L.J., McFarlane, A.C., 2000. Suicidal ideation in a random community sample: attributable risk due to depression and psychosocial and traumatic events. Aust. N. Z. J. Psychiatry 34, 98-106.

Grover, K.E., Green, K.L., Pettit, J.W., Monteith, L.L., Garza, M.J., Venta, A., 2009. Problem solving moderates the effects of life event stress and chronic stress on suicidal behaviors in adolescence. J. Clin. Psychol. 65, 1281-1290. doi:10.1002/jclp.20632

Gvion, Y., Apter, A., 2011. Aggression, impulsivity, and suicide behavior: a review of the literature. Arch. Suicide Res. Off. J. Int. Acad. Suicide Res. 15, 93-112. doi:10.1080/13811118.2011.565265

Gvion, Y., Horesh, N., Levi-Belz, Y., Apter, A., 2015. A proposed model of the development of suicidal ideations. Compr. Psychiatry 56, 93-102. doi:10.1016/j.comppsych.2014.09.019

Huffman, J.C., DuBois, C.M., Healy, B.C., Boehm, J.K., Kashdan, T.B., Celano, C.M., Denninger, J.W., Lyubomirsky, S., 2014. Feasibility and utility of positive psychology exercises for suicidal inpatients. Gen. Hosp. Psychiatry 36, 88-94. doi:10.1016/j.genhosppsych.2013.10.006

Joe, S., Romer, D., Jamieson, P.E., 2007. Suicide acceptability is related to suicide planning in U.S. adolescents and young adults. Suicide Life. Threat. Behav. 37, 165-178. doi:10.1521/suli.2007.37.2.165

Joiner, T.E., Rudd, M.D., 1995. Negative attributional style for interpersonal events and the occurrence of severe interpersonal disruptions as predictors of self-reported suicidal ideation. Suicide Life. Threat. Behav. 25, 297-304.

Jollant, F., Guillaume, S., Jaussent, I., Castelnau, D., Malafosse, A., Courtet, P., 2007. Impaired decision-making in suicide attempters may increase the risk of problems in affective relationships. J. Affect. Disord. 99, 59-62. doi:10.1016/j.jad.2006.07.022

Kattimani, S., Sarkar, S., Rajkumar, R.P., Menon, V., 2015. Stressful life events, hopelessness, and coping strategies among impulsive suicide attempters. J. Neurosci. Rural Pract. 6, 171-176. doi:10.4103/09763147.153222

Kelly, T.M., Soloff, P.H., Lynch, K.G., Haas, G.L., Mann, J.J., 2000. Recent life events, social adjustment, and suicide attempts in patients with major depression and borderline personality disorder. J. Personal. Disord. 14, 316-326.

Khan, M.M., Mahmud, S., Karim, M.S., Zaman, M., Prince, M., 2008. Case-control study of suicide in Karachi, Pakistan. Br. J. Psychiatry J. Ment. Sci. 193, 402-405. doi:10.1192/bjp.bp.107.042069 
Kleiman, E.M., Riskind, J.H., Schaefer, K.E., 2014. Social support and positive events as suicide resiliency factors: examination of synergistic buffering effects. Arch. Suicide Res. Off. J. Int. Acad. Suicide Res. 18, 144 155. doi: $10.1080 / 13811118.2013 .826155$

Kumar, C.T.S., Mohan, R., Ranjith, G., Chandrasekaran, R., 2006. Characteristics of high intent suicide attempters admitted to a general hospital. J. Affect. Disord. 91, 77-81. doi:10.1016/j.jad.2005.12.028

Laglaoui, C.B., Calati, R., Guillaume, S., Courtet, P., 2016. Do reasons for living protect against suicidal thoughts and behaviors? A systematic review of the literature. J. Psychiatr. Res. 77, 92-108. doi:10.1016/j.jpsychires.2016.02.019

Li, X.Y., Phillips, M.R., Zhang, Y.P., Xu, D., Yang, G.H., 2008. Risk factors for suicide in China's youth: a casecontrol study. Psychol. Med. 38, 397-406. doi:10.1017/S0033291707001407

Linehan, M.M., Goodstein, J.L., Nielsen, S.L., Chiles, J.A., 1983. Reasons for staying alive when you are thinking of killing yourself: the reasons for living inventory. J. Consult. Clin. Psychol. 51, 276-286.

Linehan, M.M., Korslund, K.E., Harned, M.S., Gallop, R.J., Lungu, A., Neacsiu, A.D., McDavid, J., Comtois, K.A., Murray-Gregory, A.M., 2015. Dialectical behavior therapy for high suicide risk in individuals with borderline personality disorder: a randomized clinical trial and component analysis. JAMA Psychiatry 72, 475-482. doi:10.1001/jamapsychiatry.2014.3039

Liu, R.T., Miller, I., 2014. Life events and suicidal ideation and behavior: a systematic review. Clin. Psychol. Rev. 34, 181-192. doi:10.1016/j.cpr.2014.01.006

Liu, X., Tein, J.-Y., 2005. Life events, psychopathology, and suicidal behavior in Chinese adolescents. J. Affect. Disord. 86, 195-203. doi:10.1016/j.jad.2005.01.016

Lopez-Castroman, J., Olié, E., Courtet, P., 2014a. Stress and Vulnerability: A Developing Model for Suicidal Risk, in: Cannon, K.E., Hudzik, T.J. (Eds.), Suicide: Phenomenology and Neurobiology. Springer International Publishing, pp. 87-100.

Lopez-Castroman, J., Jaussent, I., Beziat, S., Guillaume, S., Baca-Garcia, E., Genty, C., Olié, E., Courtet, P., 2014b. Increased severity of suicidal behavior in impulsive aggressive patients exposed to familial adversities. Psychol. Med. 44, 3059-3068. doi:10.1017/S0033291714000646

Mann, J.J., Arango, V.A., Avenevoli, S., Brent, D.A., Champagne, F.A., Clayton, P., Currier, D., Dougherty, D.M., Haghighi, F., Hodge, S.E., Kleinman, J., Lehner, T., McMahon, F., Mościcki, E.K., Oquendo, M.A., Pandey, G.N., Pearson, J., Stanley, B., Terwilliger, J., Wenzel, A., 2009. Candidate endophenotypes for genetic studies of suicidal behavior. Biol. Psychiatry 65, 556-563. doi:10.1016/j.biopsych.2008.11.021

Mann, J.J., Waternaux, C., Haas, G.L., Malone, K.M., 1999. Toward a clinical model of suicidal behavior in psychiatric patients. Am. J. Psychiatry 156, 181-189.

McGirr, A., Alda, M., Séguin, M., Cabot, S., Lesage, A., Turecki, G., 2009. Familial aggregation of suicide explained by cluster B traits: a three-group family study of suicide controlling for major depressive disorder. Am. J. Psychiatry 166, 1124-1134. doi:10.1176/appi.ajp.2009.08111744

McGirr, A., Turecki, G., 2007. The relationship of impulsive aggressiveness to suicidality and other depressionlinked behaviors. Curr. Psychiatry Rep. 9, 460-466.

Melhem, N.M., Brent, D.A., Ziegler, M., Iyengar, S., Kolko, D., Oquendo, M., Birmaher, B., Burke, A., Zelazny, J., Stanley, B., Mann, J.J., 2007. Familial pathways to early-onset suicidal behavior: familial and individual antecedents of suicidal behavior. Am. J. Psychiatry 164, 1364-1370. doi:10.1176/appi.ajp.2007.06091522

Milner, A.J., Carter, G., Pirkis, J., Robinson, J., Spittal, M.J., 2015. Letters, green cards, telephone calls and postcards: systematic and meta-analytic review of brief contact interventions for reducing self-harm, suicide attempts and suicide. Br. J. Psychiatry J. Ment. Sci. 206, 184-190. doi:10.1192/bjp.bp.114.147819

O'Connor, R.C., Nock, M.K., 2014. The psychology of suicidal behaviour. Lancet Psychiatry 1, 73-85. doi:10.1016/S2215-0366(14)70222-6

Olié, E., Guillaume, S., Jaussent, I., Courtet, P., Jollant, F., 2010. Higher psychological pain during a major depressive episode may be a factor of vulnerability to suicidal ideation and act. J. Affect. Disord. 120, 226230. doi:10.1016/j.jad.2009.03.013 
Oquendo, M.A., Galfalvy, H., Russo, S., Ellis, S.P., Grunebaum, M.F., Burke, A., Mann, J.J., 2004. Prospective study of clinical predictors of suicidal acts after a major depressive episode in patients with major depressive disorder or bipolar disorder. Am. J. Psychiatry 161, 1433-1441. doi:10.1176/appi.ajp.161.8.1433

Park, S., Hatim Sulaiman, A., Srisurapanont, M., Chang, S.-M., Liu, C.-Y., Bautista, D., Ge, L., Choon Chua, H., Pyo Hong, J., Mood Disorders Research: Asian \& Australian Network, 2015. The association of suicide risk with negative life events and social support according to gender in Asian patients with major depressive disorder. Psychiatry Res. 228, 277-282. doi:10.1016/j.psychres.2015.06.032

Patton, J.H., Stanford, M.S., Barratt, E.S., 1995. Factor structure of the Barratt impulsiveness scale. J. Clin. Psychol. 51, 768-774.

Pompili, M., Serafini, G., Innamorati, M., Montebovi, F., Palermo, M., Campi, S., Stefani, H., Giordano, G., Telesforo, L., Amore, M., Girardi, P., 2012. Car accidents as a method of suicide: a comprehensive overview. Forensic Sci. Int. 223, 1-9. doi:10.1016/j.forsciint.2012.04.012

Rich, A.R., Bonner, R.L., 1987. Concurrent validity of a stress-vulnerability model of suicidal ideation and behavior: a follow-up study. Suicide Life. Threat. Behav. 17, 265-270.

Rubenowitz, E., Waern, M., Wilhelmson, K., Allebeck, P., 2001. Life events and psychosocial factors in elderly suicides--a case-control study. Psychol. Med. 31, 1193-1202.

Sheehan, D.V., Lecrubier, Y., Sheehan, K.H., Amorim, P., Janavs, J., Weiller, E., Hergueta, T., Baker, R., Dunbar, G.C., 1998. The Mini-International Neuropsychiatric Interview (M.I.N.I.): the development and validation of a structured diagnostic psychiatric interview for DSM-IV and ICD-10. J. Clin. Psychiatry 59 Suppl 20, 22-33-57.

Slama, F., Courtet, P., Golmard, J.L., Mathieu, F., Guillaume, S., Yon, L., Jollant, F., Misson, H., Jaussent, I., Leboyer, M., Bellivier, F., 2009. Admixture analysis of age at first suicide attempt. J. Psychiatr. Res. 43, 895-900. doi:10.1016/j.jpsychires.2009.01.007

Sun, L., Zhang, J., 2015. Coping skill as a moderator between negative life events and suicide among young people in rural China. J. Clin. Psychol. 71, 258-266. doi:10.1002/jclp.22140

Turvey, C., Stromquist, A., Kelly, K., Zwerling, C., Merchant, J., 2002. Financial loss and suicidal ideation in a rural community sample. Acta Psychiatr. Scand. 106, 373-380.

Umamaheswari, V., Avasthi, A., Grover, S., 2014. Risk factors for suicidal ideations in patients with bipolar disorder. Bipolar Disord. 16, 642-651. doi:10.1111/bdi.12179

Vijayakumar, L., Rajkumar, S., 1999. Are risk factors for suicide universal? A case-control study in India. Acta Psychiatr. Scand. 99, 407-411.

Wan, G.W.Y., Leung, P.W.L., 2010. Factors accounting for youth suicide attempt in Hong Kong: a model building. J. Adolesc. 33, 575-582. doi:10.1016/j.adolescence.2009.12.007

Wang, Y., Sareen, J., Afifi, T.O., Bolton, S.-L., Johnson, E.A., Bolton, J.M., 2015. A population-based longitudinal study of recent stressful life events as risk factors for suicidal behavior in major depressive disorder. Arch. Suicide Res. Off. J. Int. Acad. Suicide Res. 19, 202-217. doi:10.1080/13811118.2014.957448

Yen, S., Pagano, M.E., Shea, M.T., Grilo, C.M., Gunderson, J.G., Skodol, A.E., McGlashan, T.H., Sanislow, C.A., Bender, D.S., Zanarini, M.C., 2005. Recent life events preceding suicide attempts in a personality disorder sample: findings from the collaborative longitudinal personality disorders study. J. Consult. Clin. Psychol. 73, 99-105. doi:10.1037/0022-006X.73.1.99

Zhang, J., Conwell, Y., Zhou, L., Jiang, C., 2004. Culture, risk factors and suicide in rural China: a psychological autopsy case control study. Acta Psychiatr. Scand. 110, 430-437. doi:10.1111/j.1600-0447.2004.00388.x

Zhang, J., Xiao, S., Zhou, L., 2010. Mental disorders and suicide among young rural Chinese: a case-control psychological autopsy study. Am. J. Psychiatry 167, 773-781. doi:10.1176/appi.ajp.2010.09101476

Zhang, W.-C., Jia, C.-X., Zhang, J.-Y., Wang, L.-L., Liu, X.-C., 2015. Negative life events and attempted suicide in rural China. PloS One 10, e0116634. doi:10.1371/journal.pone.0116634 
Table 1. Socio-demographic and clinical characteristics according to the presence or absence of current suicidal ideation.

\begin{tabular}{|c|c|c|c|c|c|c|}
\hline & \multicolumn{2}{|c|}{$\begin{array}{c}\text { Current } S S I<2 \\
\quad N=208\end{array}$} & \multicolumn{2}{|c|}{$\begin{array}{c}\text { Current } S S I \geq 2 \\
\quad N=130\end{array}$} & \multirow[b]{2}{*}{ OR $[95 \% C I]$} & \multirow[b]{2}{*}{ P-value } \\
\hline Variable & $N$ & $\%$ & $n$ & $\%$ & & \\
\hline Age (years), Median [Min-Max] & \multicolumn{2}{|c|}{$42.57(15.06-68.79)$} & \multicolumn{2}{|c|}{$42.23(18.42-66.20)$} & $0.99[0.97 ; 1.01]$ & 0.24 \\
\hline \multicolumn{7}{|l|}{ Sex } \\
\hline Male & 91 & 43.75 & 27 & 20.77 & 1 & $<0.0001$ \\
\hline Female & 117 & 56.25 & 103 & 79.23 & $2.97[1.79 ; 4.91]$ & \\
\hline \multicolumn{7}{|l|}{ Marital status } \\
\hline Single & 109 & 52.40 & 77 & 59.23 & 1 & 0.22 \\
\hline In couple & 99 & 47.60 & 53 & 40.77 & $0.76[0.49 ; 1.18]$ & \\
\hline \multicolumn{7}{|l|}{ Level of education (years) } \\
\hline$<12$ & 70 & 33.65 & 41 & 31.54 & 1 & 0.68 \\
\hline$\geq 12$ & 138 & 66.35 & 89 & 68.46 & $1.10[0.69 ; 1.76]$ & \\
\hline \multicolumn{7}{|l|}{ Tobacco use } \\
\hline No & 76 & 36.54 & 43 & 33.08 & 1 & 0.36 \\
\hline Current smoker & 93 & 44.71 & 68 & 52.31 & $1.29[0.79 ; 2.10]$ & \\
\hline Past smoker & 39 & 18.75 & 19 & 14.62 & $0.86[0.44 ; 1.67]$ & \\
\hline
\end{tabular}

Bipolar spectrum

\begin{tabular}{clllllll}
\hline No & 151 & 72.60 & 89 & 68.46 & 1 & 0.42 \\
\hline \multirow{2}{*}{ Yes } & 57 & 27.40 & 41 & 31.54 & $1.22[0.76 ; 1.97]$ & \\
\hline & & & & & & 0.87 \\
\hline & No & 67 & 32.21 & 43 & 33.08 & 1 & $0.96[0.60 ; 1.53]$ \\
\hline
\end{tabular}

BDI score

$\begin{array}{lllllll}<15 \text { (no severe depression) } & 127 & 61.06 & 17 & 13.18 & 1 & <\mathbf{0 . 0 0 0 1} \\ \geq 15 \text { (severe depression) } & 81 & 38.94 & 112 & 86.82 & 10.33[5.78 ; 18.5] & \end{array}$

Substance use

$\begin{array}{lllllll}\text { No } & 169 & 81.25 & 108 & 83.08 & 1 & 0.67 \\ \text { Yes } & 39 & 18.75 & 22 & 16.92 & 0.88[0.50 ; 1.57] & \end{array}$




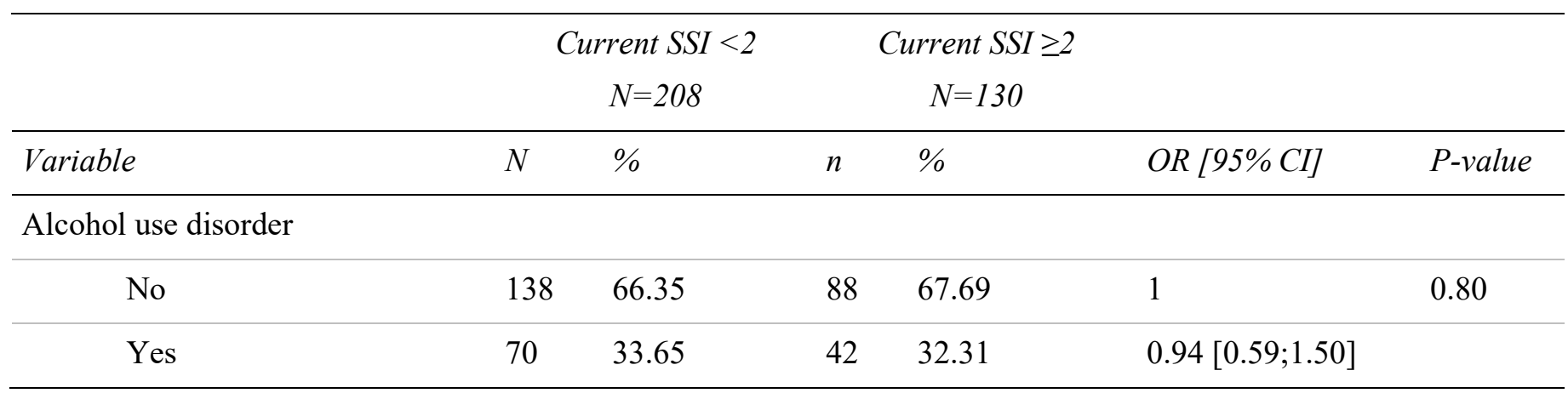

BDI: Beck Depression Inventory; MDD: Major Depressive Disorder; Max: maximum; Min:

Minimum; SSI: Scale for Suicidal Ideation 
Table 2. Personal and family suicidal behavior, personality traits and childhood trauma in patients with or without current suicidal ideation

\begin{tabular}{|c|c|c|c|c|c|c|}
\hline \multicolumn{7}{|c|}{ Current SSI } \\
\hline & & $<2$ & & $\geq 2$ & & \\
\hline & & $N=208$ & & $N=130$ & & \\
\hline Variable & $n$ & $\%$ & $n$ & $\%$ & OR $[95 \% C I]$ & P-value \\
\hline \multicolumn{7}{|l|}{ Familial history of suicidal behavior } \\
\hline No & 119 & 57.21 & 69 & 53.08 & 1 & 0.46 \\
\hline Yes & 89 & 42.79 & 61 & 46.92 & $1.18[0.76 ; 1.84]$ & \\
\hline \multicolumn{7}{|l|}{ Number of SA } \\
\hline 1 or 2 & 164 & 78.85 & 77 & 59.23 & 1 & 0.0001 \\
\hline 3 or more & 44 & 21.15 & 53 & 40.77 & $2.57[1.58 ; 4.16]$ & \\
\hline \multicolumn{7}{|l|}{ Age at first SA (years) } \\
\hline$>26$ & 129 & 62.02 & 71 & 54.62 & 1 & 0.18 \\
\hline$\leq 26$ & 79 & 37.98 & 59 & 45.38 & $1.36[0.87 ; 2.12]$ & \\
\hline BIS-10 - Total score ${ }^{(1)}$ & & $55(24-106)$ & & $61(19-107)$ & $1.02[1.01 ; 1.03]$ & 0.003 \\
\hline $\begin{array}{l}\text { Hopelessness scale - Sum of } 20 \text { items } \\
\text { (1) }\end{array}$ & & $9(0-20)$ & & $15(2-20)$ & $1.24[1.17 ; 1.31]$ & $<0.0001$ \\
\hline \multicolumn{7}{|l|}{ CTQ- Emotional Abuse } \\
\hline None, Low & 131 & 64.85 & 68 & 53.13 & 1 & 0.03 \\
\hline Moderate, Severe & 71 & 35.15 & 60 & 46.88 & $1.63[1.04 ; 2.56]$ & \\
\hline \multicolumn{7}{|l|}{ CTQ- Sexual Abuse } \\
\hline None, Low & 154 & 75.86 & 86 & 67.72 & 1 & 0.11 \\
\hline Moderate, Severe & 49 & 24.14 & 41 & 32.28 & $1.50[0.92 ; 2.45]$ & \\
\hline \multicolumn{7}{|l|}{ CTQ- Physical Neglect } \\
\hline None, Low & 148 & 74.37 & 82 & 64.06 & 1 & 0.05 \\
\hline Moderate, Severe & 51 & 25.63 & 46 & 35.94 & $1.63[1.01 ; 2.63]$ & \\
\hline \multicolumn{7}{|l|}{ CTQ- Emotional Neglect } \\
\hline None, Low & 128 & 64.00 & 70 & 54.69 & 1 & 0.09 \\
\hline Moderate, Severe & 72 & 36.00 & 58 & 45.31 & $1.47[0.94 ; 2.32]$ & \\
\hline
\end{tabular}

CTQ- Physical Abuse 


\begin{tabular}{|c|c|c|c|c|c|c|}
\hline \multicolumn{7}{|c|}{ Current SSI } \\
\hline & & $<2$ & & $\geq 2$ & & \\
\hline & & $N=208$ & & $N=130$ & & \\
\hline Variable & $n$ & $\%$ & $n$ & $\%$ & OR $[95 \% C I]$ & $P$-value \\
\hline None, Low & 169 & 82.04 & 96 & 75.00 & 1 & 0.12 \\
\hline Moderate, Severe & 37 & 17.96 & 32 & 25.00 & $1.52[0.89 ; 2.60]$ & \\
\hline
\end{tabular}

BIS-10: Barrat Impulsiveness Scale (10th version); CTQ: Child Trauma Questionnaire; SA: Suicide Attempts; SSI: Scale for Suicidal Ideation. 
Table 3. Life events, reasons for living and current suicidal ideation.

\begin{tabular}{|c|c|c|c|c|c|c|c|c|}
\hline \multirow[b]{4}{*}{ Variable } & \multicolumn{2}{|c|}{ Current SSI } & & & & & & \\
\hline & & \multirow{2}{*}{$\begin{array}{l}\geq 2 \\
N=130\end{array}$} & \multirow{2}{*}{\multicolumn{2}{|c|}{ Model 1}} & \multirow{2}{*}{\multicolumn{2}{|c|}{ Model 2}} & \multirow{2}{*}{\multicolumn{2}{|c|}{ Model 3}} \\
\hline & $N=208$ & & & & & & & \\
\hline & $n \quad \%$ & $n$ & OR $[95 \% C I]$ & $P$ & \multirow[t]{2}{*}{ OR $[95 \% \mathrm{CI}]$} & $P$ & OR $[95 \% \mathrm{CI}]$ & P-value \\
\hline \multicolumn{8}{|c|}{ LifeEvent - Family-related life events } & \\
\hline Number of PLE ${ }^{(1)}$ & $2(0-6)$ & $1(0-5)$ & $0.73[0.59 ; 0.90]$ & 0.004 & $0.73[0.58 ; 0.91]$ & 0.005 & $0.73[0.58 ; 0.91]$ & 0.006 \\
\hline Number of NLE ${ }^{(1)}$ & $3(0-10)$ & $3(0-11)$ & $0.96[0.84 ; 1.11]$ & 0.60 & $0.92[0.80 ; 1.07]$ & 0.27 & $0.92[0.79 ; 1.08]$ & 0.32 \\
\hline \multicolumn{9}{|c|}{ LifeEvent - School, student or profession-related life events } \\
\hline Number of PLE ${ }^{(1)}$ & $0(0-2)$ & $0(0-4)$ & $0.90[0.60 ; 1.35]$ & 0.61 & $0.95[0.62 ; 1.44]$ & 0.79 & $0.93[0.60 ; 1.43]$ & 0.73 \\
\hline Number of NLE ${ }^{(1)}$ & $1(0-3)$ & $1(0-4)$ & $1.24[0.89 ; 1.74]$ & 0.21 & $1.22[0.86 ; 1.72]$ & 0.26 & $1.30[0.91 ; 1.86]$ & 0.15 \\
\hline \multicolumn{9}{|c|}{$\begin{array}{l}\text { LifeEvent - Social and religion-related life } \\
\text { events }\end{array}$} \\
\hline Number of PLE ${ }^{(1)}$ & $1(0-5)$ & $1(0-4)$ & $0.89[0.68 ; 1.16]$ & 0.39 & $0.90[0.68 ; 1.18]$ & 0.44 & $0.93[0.70 ; 1.23]$ & 0.61 \\
\hline Number of NLE ${ }^{(1)}$ & $2(0-7)$ & $2(0-7)$ & $1.05[0.85 ; 1.28]$ & 0.66 & $1.04[0.85 ; 1.29]$ & 0.69 & $1.07[0.86 ; 1.33]$ & 0.54 \\
\hline \multicolumn{9}{|c|}{ LifeEvent - Health-related life events } \\
\hline Number of PLE ${ }^{(1)}$ & $0(0-1)$ & $0(0-2)$ & $0.60[0.13 ; 2.79]$ & 0.51 & $0.57[0.12 ; 2.72]$ & 0.49 & $0.63[0.13 ; 2.97]$ & 0.56 \\
\hline Number of NLE ${ }^{(1)}$ & $0(0-2)$ & $0(0-2)$ & $1.85[1.02 ; 3.36]$ & 0.04 & $1.90[1.03 ; 3.50]$ & 0.04 & $2.01[1.04 ; 3.92]$ & 0.04 \\
\hline \multicolumn{9}{|l|}{ LifeEvent (All) } \\
\hline Number of PLE ${ }^{(1)}$ & $4[0-11]$ & $3[0-8]$ & $0.85[0.74 ; 0.97]$ & 0.01 & $0.85[0.74 ; 0.98]$ & 0.02 & $0.85[0.74 ; 0.98]$ & 0.03 \\
\hline Number of NLE ${ }^{(1)}$ & $5[1-17]$ & $6[1-16]$ & $1.02[0.94 ; 1.12]$ & 0.61 & $1.01[0.92 ; 1.10]$ & 0.92 & $1.02[0.92 ; 1.12]$ & 0.71 \\
\hline
\end{tabular}




\begin{tabular}{|c|c|c|c|c|c|c|c|c|}
\hline \multirow[b]{4}{*}{ Variable } & \multicolumn{2}{|c|}{ Current SSI } & & & & & & \\
\hline & & & \multirow{2}{*}{\multicolumn{2}{|c|}{ Model 1}} & \multirow{2}{*}{\multicolumn{2}{|c|}{ Model 2}} & \multirow{2}{*}{ Model 3} & \\
\hline & $N=208$ & $N=130$ & & & & & & \\
\hline & $n \quad \%$ & $n$ & OR $[95 \% C I]$ & $P$ & OR $[95 \% C I]$ & $P$ & OR $[95 \% C I]$ & P-value \\
\hline RFLI - Total score & $176(72-261)$ & $\begin{array}{l}131.5(55- \\
251)\end{array}$ & $0.98[0.97 ; 0.98]$ & $<0.0001$ & $0.98[0.97 ; 0.99]$ & $<0.0001$ & $0.98[0.97 ; 0.98]$ & $<0.0001$ \\
\hline $\begin{array}{l}\text { RFLI - Score on Survival and Coping } \\
\text { Beliefs }^{(1)}\end{array}$ & $89(24-142)$ & $54(24-130)$ & $0.96[0.95 ; 0.97]$ & $<\mathbf{0 . 0 0 0 1}$ & $0.96[0.95 ; 0.98]$ & $<0.0001$ & $0.96[0.95 ; 0.97]$ & $<0.0001$ \\
\hline $\begin{array}{l}\text { RFLI - Score on Responsibility to } \\
\text { Family }^{(1)}\end{array}$ & $34(9-42)$ & $28(7-42)$ & $0.95[0.92 ; 0.98]$ & 0.0005 & $0.95[0.92 ; 0.98]$ & 0.002 & $0.95[0.92 ; 0.98]$ & 0.003 \\
\hline RFLI - Score on Child-related Concerns ${ }^{(1)}$ & $16(3-18)$ & $12(3-18)$ & $0.88[0.83 ; 0.92]$ & $<0.0001$ & $0.87[0.83 ; 0.92]$ & $<0.0001$ & $0.86[0.82 ; 0.91]$ & $<0.0001$ \\
\hline RFLI - Score on Fear of Suicide ${ }^{(1)}$ & $20(7-42)$ & $20(7-38)$ & $0.98[0.95 ; 1.02]$ & 0.36 & $0.98[0.95 ; 1.02]$ & 0.31 & $0.98[0.95 ; 1.02]$ & 0.36 \\
\hline $\begin{array}{l}\text { RFLI - Score on Fear of Social } \\
\text { Disapproval }^{(1)}\end{array}$ & $8(3-18)$ & $5(3-18)$ & $0.92[0.87 ; 0.98]$ & 0.007 & $0.92[0.86 ; 0.98]$ & 0.007 & $0.92[0.86 ; 0.98]$ & 0.01 \\
\hline $\begin{array}{l}\text { RFLI - Score on Moral Objections to } \\
\text { Suicide }^{(1)}\end{array}$ & $6(4-24)$ & $5(4-24)$ & $0.94[0.88 ; 1.00]$ & 0.04 & $0.94[0.89 ; 1.01]$ & 0.07 & $0.93[0.87 ; 1.00]$ & 0.04 \\
\hline
\end{tabular}

${ }^{(1)}$ Continuous variables were expressed by median [minimum value-maximum value]

Model 1 was adjusted for center, sex and BDI score

Model 2 was adjusted for covariates of model 1 plus CTQ-Emotional abuse, CTQ-Physical neglect and CTQ-Emotional neglect.

Model 3 was adjusted for the covariates of model 2 plus SA number and BIS-10 score

BDI: Beck Depression Inventory; BIS-10: Barrat Impulsiveness Scale (10th version); CTQ: Child Trauma Questionnaire; NLE: Negative Life Events; PLE: Positive Life Events; SA: Suicide Attempts; SSI: Scale for Suicidal Ideation 
Table 4: Analysis of synergistic or additive effects of number of Family-related Positive Life Events and Reasons for Living on suicidal ideation.

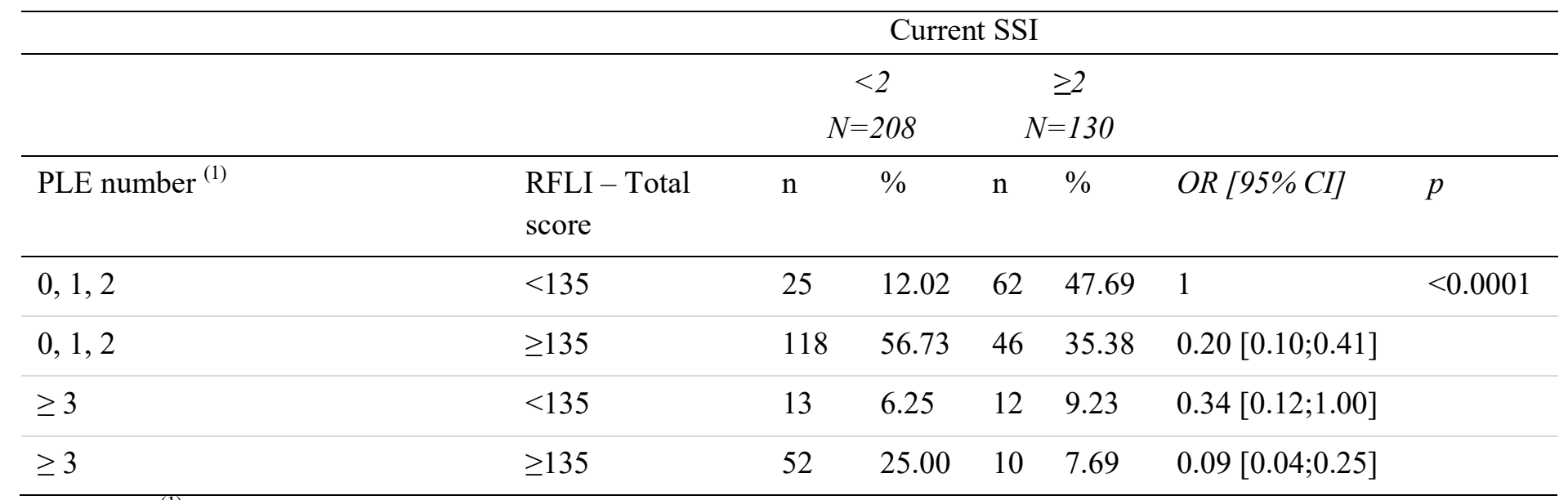

${ }^{(1)}$ Family-related life events

Model 1 was adjusted for center, sex and BDI score, CTQ-Emotional abuse, CTQ-Physical neglect and CTQEmotional neglect, plus SA number and BIS-10 score

PLE: Positive Life Events; SSI: Scale for Suicidal Ideation 